\title{
NIETZSCHE E A CONSTRUÇÃO MESSIÂNICA DO WAGNERIANISMO
}

Fabiano de Lemos Britto ${ }^{1}$

RESUMO: A história da relação equívoca entre Nietzsche e Wagner revela as dimensões de sua frágil tensão, se considerada segundo os elementos com base nos quais ambos conceberam o problema da cultura e sua renovação como missão política e teórica. O presente artigo pretende, a partir da leitura de documentos testemunhais, sublinhar a distância ideológica que o filólogo e o compositor, estrategicamente, tiveram de ignorar. Mostram-se, através desta análise, as diferenças normalmente pouco abordadas entre os projetos de reforma da cultura elaborados pelos dois autores - tanto no que se refere à atuação política, quanto no que diz respeito a uma visão de mundo.

PALAVRAS-CHAVE: Nietzsche. Wagner. Cultura. Bildung.

Alle Wahrheit ist uralt.

Novalis.

\section{Primeiros contatos}

Do momento em que assume sua cátedra de Filologia, em 1869, àquele em que testemunha, decepcionado, a difícil inauguração do Festival de Bayreuth, em 1876, Nietzsche constrói com Wagner a instável história de uma amizade, atravessada de equívocos, adesões, devoções, desconfianças.

\footnotetext{
${ }^{1}$ Doutor em Filosofia. Professor do Departamento de Educação da PUC-Rio. E-mail: fabianolemos@gmail.com
} 
Dos raros contatos pessoais, essencialmente epistolares, após essa data, nenhum foi suficientemente capaz de levar a cabo uma reaproximação - e a amizade deixa de ser um fato presente, vivido, para se tornar, para ambos, em menor ou maior grau de violência - objeto de reflexão de suas próprias trajetórias pessoais ${ }^{2}$. Cosima Wagner havia pressentido desde muito cedo e exemplarmente a fragilidade dessa relação, prescrevendo, ansiosamente, o cuidado com que ambos deveriam sondar o outro: "Acredite-me quando digo que não pode haver indiferença ou mal-entendidos entre os dois. Confesso que tenho estado muito inquieta em relação a isto, mas estou agora convencida de que tal nunca pode acontecer". ${ }^{3}$ Durante os sete anos de amizade, seria impossível cumprir tais exigências de atenção, e os desentendimentos se multiplicaram por todo esse período - na maior parte das vezes, sublimados pela habilidade conciliatória de Cosima. É sob o signo de uma diferença insistentemente recalcada que sua história pode ser entendida.

De todo modo, o tom em que essa amizade tem início é bem outro. O fato é que, mesmo antes de conhecer pessoalmente o músico, Nietzsche já lhe concedia uma comedida, mas firme simpatia. Uma anotação de seus cadernos de estudante de 1867-68, relativamente longa, toma partido, explicitamente, das composições de Wagner. Ainda não se trata aqui, é claro, de suas concepções estéticas, mas há um acento sobre o modo como o músico desenvolve seu trabalho como projeto e sobre sua particularidade frente a um tempo carente de renovações:

A estética musical vai de mal a pior: falta-lhe um Lessing que marque seus limites [Grenzen] em relação à poesia. Em nenhuma outra parte sente-se isso mais nitidamente que nos compositores poetas

\footnotetext{
${ }^{2}$ É muito difícil decidir até que ponto Wagner considerou relevante a amizade de Nietzsche, em sua vida. Durante o período de convivência íntima, sua correspondência e os diários anotados por sua esposa Cosima não deixam de atestar a reciprocidade dessa amizade. Mas, após a ruptura, apenas algumas menções são feitas, todas por parte de Cosima. Enquanto Nietzsche nunca deixou de pensar o significado dessa relação, mesmo após sua radical mudança de sentido, o silêncio de Wagner deixa margem a interpretações como as de Martin Gregor-Dellin, que afirma que "O caso Nietzsche foi na vida de Wagner apenas um episódio. Para Nietzsche ele significou mais [...]" (Richard Wagner: Sein Leben - Sein Werk - Sein Jahrhundert. München: Piper, 1980, p. 622); ou a de Elisabeth FörsterNietzsche, que afirma, quase literalmente, a mesma coisa: "Esta amizade significou, indiscutivelmente, mais para meu irmão do que para Wagner" (FÖRSTER-NIETZSCHE, E. Wagner und Nietzsche zur Zeit ihr Freundschaft. München: [s.n.], 1915, p. 330). De todo modo, é impossível definir, de uma vez por todas, a resposta a esse problema,
} justamente pela ausência de dados objetivos para isso.

${ }^{3}$ Carta de Cosima a Nietzsche, de 1873, .In FÖERSTER-NIETZSCHE, E. op. cit., p. 170, grifos meus 


\begin{abstract}
[Dichterkomponisten] cujas obras de juventude se colocam diante de nós. O que é mais indicado aqui é observar a ligação de uma obra de arte com a vida e o percurso de formação [Bildungsganges] de seu criador - nesse ponto ele pode se ofender, e com razão. Esta referida formação ainda não está terminada em Richard Wagner, seu último fruto, que o sol de um novo princípio [eines neuen Principes] revelaria, ainda não apareceu. Todo juízo sobre suas atividades globais [Gesamtthätigkeit] é, portanto, um pré-juízo [Vorurtheil]; a crítica de seus trabalhos isolados não deve ser feita a partir das luzes turvas dos pré-juízos. ${ }^{4}$
\end{abstract}

No dia oito de novembro de 1868, Nietzsche encontra Richard Wagner pela primeira vez, em Leipzig, em uma reunião organizada por Hermann Brockhaus, professor orientalista, sob cuja orientação Ernst Windisch, seu colega de universidade, preparava o exame final..$^{5}$ Esse primeiro encontro logo assume para Nietzsche a qualidade de uma conversão, que é, a um só tempo, real e fantástica. É nesses termos que o episódio é narrado a Rhode:

Contarei a você apenas rapidamente o que essa tarde ofereceu, verdadeiras alegrias do tipo particularmente mais interessante, de modo que eu ainda hoje não estou em meus velhos eixos e não posso fazer nada melhor que contar a você, meu mais caro amigo, e relatarlhe essa "maravilhosa lenda" [wundersame Mär]. ${ }^{6}$

É em um registro mítico, portanto, que Nietzsche irá, reconhecidamente, localizar a origem dessa relação. Ela nunca deixará de girar em torno desse mesmo ponto de partida. Wagner é a presença do gênio, ele é a garantia da possibilidade efetiva, embora fantástica, dessa figura que guarda consigo, contra a miséria do tempo e dos contemporâneos, a ideia intocada, eterna, da verdadeira cultura, a que se abre como um segredo apenas aos poucos homens cultivados. Até então, tal imagem só se apresentava a Nietzsche por via do classicismo de Goethe ou Schiller, da grandiosidade tão distante dos gregos e, muito especialmente, da irascível filosofia de Schopenhauer; todos urgentes, mas intangíveis. Toda a cultura alemã, como cultura universal, que Nietzsche e um estreito círculo de intelectuais se impôs como tarefa defender, se ressentia até essa época,

${ }^{4}$ NIETZSCHE, F. Werke - Historisch-Kritisch Gesamtausgabe. München: C. B. Beck, 19331942. (= HKG) III, 207.

${ }^{5} \mathrm{O}$ encontro é narrado com detalhes na longa carta a Rhode, enviada no dia seguinte (Sämtliche Briefe. Kristische Studienausgabe in 8 Bänden. Berlin und New York: Walter de Gruyter, 1986 (= KSB) II, 335-342).

${ }^{6}$ KSB II, 340 . 
justamente, da ausência de efetividade. A "lenda" que narra o fim dessa ausência e a promessa possível de uma renovação da cultura começa exatamente quando Wagner passa a ocupar, com o direito de gênio que lhe cabe, o espaço de uma nova origem. O encontro em Leipzig pontua o novo tempo, e é provável que a teogonia que a ele passa a se vincular tenha como condição de emergência o momento em que o músico denuncia sua própria dinastia: Wagner conversa com Nietzsche sobre Schopenhauer: "[...] tive uma longa conversa com ele sobre Schopenhauer: ah, e você imagina que felicidade foi para mim escutá-lo falar disso com tal indescritível calor, o que ele [Wagner] lhe deve, como ele é o único filósofo que reconheceu a essência da música $[\ldots]^{\prime \prime}{ }^{7}$

\section{Mitificações}

A associação entre Wagner e Schopenhauer torna-se inevitável. Se tivermos em conta o modo como, ainda muito depois do encontro de 1868, Nietzsche considerava a filosofia deste último como algo extraordinariamente desvinculado de seu tempo, com uma existência real imediatamente incompreensível, podemos entender melhor o impacto que essa conversa pôde realizar. Em dois fragmentos da época da composição de Schopenhauer como educador - verão de 1874 -, é esse o questionamento que se levanta: "Esse problema será justamente observado em detalhes: como Schopenhauer suportou seu tempo, sem ao menos fazer uma tentativa de ser seu reformador?"; e mais adiante: "Espanto [Verwunderung] que Schopenhauer possa simplesmente ter surgido e existido". ${ }^{8}$ Para esses dois problemas, Nietzsche encontrará, insistentemente, a resposta na figura de Wagner. Um mês após o primeiro encontro, a conexão entre um gênio e outro já está explicitamente consolidada, apoiando-se não mais na efemeridade de um "feliz encontro", mas naquilo de que ele é apenas signo. Como nos informa a carta que, ainda de Leipzig, é enviada a Erwin Rhode: "Wagner, como o conheço agora, por sua música, sua poesia, sua estética, não, minimamente, pelo feliz encontro com ele, é a ilustração mais encarnada [die leibhaftigste Illustration] daquilo que Schopenhauer chamou de gênio". ${ }^{9}$ Essa conexão, que muito rapidamente se caracterizou como a passagem de uma filosofia da cultura para um projeto possível de reforma cultural profundamente amplo,

\footnotetext{
${ }^{7}$ KSB II, 340-341.

${ }^{8}$ Fragmentos 34 [43] e 34 [47], respectivamente: Sämtliche Werke. Kristische Studienausgabe in 15 Bänden, Berlin und New York: Walter de Gruyter, 1980 (=KSA) VII 806 e 807.

${ }^{9} \mathrm{KSB}$ II, 352.
} 
tornou-se o mais forte elo nessa amizade, multiplicando-se sob diversas formas e estendendo-se, invariavelmente, por todo o período em que ela foi possível. $^{10}$

A relação que se estabeleceu entre Nietzsche e Wagner parece ter ultrapassado, assim, o quadro de uma amizade entre dois intelectuais que se admiravam mutuamente. Por parte de ambos, há uma espécie de projeção daquilo que cada um entendia por um novo e, ao mesmo tempo, ideal tipo de homem: aquilo que ambos encontravam ao se dirigir ao outro era precisamente o futuro da cultura alemã. O que aos poucos se mostrou incontornável foi a diferença entre as duas concepções desse homem e dessa cultura, enevoada pelo entusiasmo dos primeiros momentos de intimidade pessoal e intelectual. A forma como Nietzsche considerou Wagner como "seu Júpiter"11 à parte qualquer leitura psicológica, fará coincidir totalmente o comprometimento ideológico de sua primeira filosofia com essa espécie de devoção pessoal à figura do músico. Como contrapartida, Wagner, que no início de sua amizade com Nietzsche já contava cinquenta e seis anos, não evitou associar o jovem professor de Basileia a um filho capaz de divulgar suas ideias sobre a música. Essa associação tornara-se mais inevitável, na medida em que seu único filho homem nascera em um dia em que Nietzsche o visitava, como várias vezes o apontou Cosima ${ }^{12}$. Em carta de 25 de junho de 1872, Wagner escreve a seu amigo:

Estritamente falando, você é o único ganho [Gewinn] que a vida me trouxe, depois de minha mulher: agora Fidi [Siegfried] acrescentouse felizmente a essas bênçãos, mas entre eles e eu falta ainda uma conexão que somente você pode construir, qualquer coisa como do filho para o neto [bedarf es eines Gliedes das nur Sie bilden können, etwa wie der Sohn zum Enkel]. ${ }^{13}$

\footnotetext{
${ }^{10}$ Os exemplos são incontáveis. Para nos atermos a apenas dois deles, podemos levar em conta a carta enviada por Nietzsche ao próprio Wagner, em 22 de maio de 1869, que diz: "Penso no senhor e em Schopenhauer quando, até o momento, me atenho à seriedade germânica [germanischen Lebensernst], a uma consideração aprofundada dessa existência tão enigmática e inquietante" (KSB III, 9); e a Paul Deussen, em fevereiro do ano seguinte, que define Wagner como "o verdadeiro irmão espiritual de Schopenhauer, que está para ele como Schiller para Kant, como um verdadeiro amigo a ter, um gênio que experimentou o destino terrivelmente sublime de surgir um século mais cedo do que poderia ser compreendido" (KSB II, 98).

${ }^{11}$ Carta a Rohde, de 15 de agosto de 1869 (KSB III, 42): "Agora vou lhe contar algo sobre meu Júpiter, sobre Richard Wagner [...]".

${ }^{12}$ Siegfried nascera durante a tarde de 6 de junho de 1869

${ }^{13}$ BORCHMEYER, D.; SALAQUARDA, J. Nietzsche und Wagner - Stationen einer epochalen Begegnung, Band 1: Briefwechsel. Frankfurt a. M.: Insel, 1994. p. 190.
} 
Em um sentido mais amplo, o que Nietzsche representava para Wagner, segundo se depreende da correspondência deste último, nos primeiros anos da década de 1870, era a consolidação do cientista-artista, ou ao menos de um intelectual sensível ao projeto de uma obra de arte total, principal estandarte de sua concepção estética. Em outras palavras, Nietzsche era o jovem e promissor exemplo de uma nova raça de homens cultivados; aquilo que, como Wagner confessa a Rhode, após ter passado uma "longa vida na pior ou, no mínimo, na mais ridícula das sociedades" poderia ser chamado, alegremente, de "um novo gênero [Genus], talvez uma $<$ nova > geração inteira". ${ }^{14}$ Mas esse gênero e essa geração deveriam estar comprometidos com aquilo que sua própria estética propunha; e é inegável que a presença de um professor universitário, reconhecido até então por sua precocidade científica, apresentando-se como entusiasmado admirador e compartilhando - ao menos no que diz respeito às linhas gerais - de um mesmo credo romântico-schopenhaueriano apresentou-se a Wagner como uma grande oportunidade de divulgar sua obra e sua visão de mundo. Quando, em 1870, a conferência A visão de mundo dionisíaca - enviada sob o título O nascimento do pensamento trágico - é lida em Tribschen, Cosima anota em seu diário, geralmente ditado por seu marido: "Traz-me uma alegria especial que as ideias de R. [Richard Wagner] possam ser expandidas nessa área" ${ }^{15}$ E mais tarde, quando o próprio Nietzsche lê os primeiros esboços do que viria a se tornar seu O nascimento da tragédia, encontramos, no mesmo diário: "[...] vê-se aqui um homem muito douto penetrado a seu modo dos pensamentos de R. [man sieht hier einen sehr begabten Menschen von R.'s Gedanken auf eigene Weise durchdrungen]" ${ }^{16}$ É claro que essa coincidência ideológica não pode ser aceita sem restrições, a não ser como um objetivo muitas vezes projetado por ambos e pouco sustentável após uma segunda avaliação. Isso se deixa perceber também pelas incontáveis reticências guardadas por Wagner e Cosima, acerca dos textos de Nietzsche, especialmente no que dizia respeito ao tratamento reservado neles a Sócrates, a Eurípides e a outros respeitáveis nomes da arte helênica. ${ }^{17}$ Por mais que Nietzsche pretendesse tornar seu o discurso de Wagner, não poderia fazê-lo

${ }^{14}$ WAGNER, R. Briefe in Originalausgabe,2 Folge. Leipzig: Breitkopf \& Härtel, 1912., Bd. XVII, p. 545 (carta de 29 de outubro de 1872).

${ }^{15}$ WAGNER, C. Die Tagebücher, 2 Bände. München : Piper, 1976-77, Bd. I, p. 330 (entrada de 26 de dezembro de 1870).

${ }^{16}$ Idem, p. 375 (entrada de 05 de abril de 1871).

${ }^{17}$ Desde muito cedo, essas discordâncias causaram desentendimentos entre o músico e o filósofo. Comentando a palestra Sócrates e a tragédia, pronunciada por Nietzsche na universidade, em $1^{\circ}$ de fevereiro de 1870, e enviada a Tribschen um pouco antes, Wagner recomenda: "Gostaria de aconselhá-lo a não tocar nunca mais nesses pontos de vista tão inacreditáveis [sehr unglaublichen Ansichten] em curtos tratados, através de 
sem comprometê-lo com sua história intelectual pessoal e, nesse sentido, sua adesão ao wagnerianismo não pôde persistir senão enquanto era a sua própria ideia de cultura que ele via aí defendida.

Não é difícil notar que as mitificações envolvidas na história da relação entre Nietzsche e Wagner encontram-se na base do projeto de renovação da cultura elaborado pelo primeiro, em seus primeiros trabalhos. É certo que, por um lado, essas mitificações fornecem o tom ou o estilo com que esse projeto pode vir a ser aí expresso. Mas a importância mais fundamental dos elementos míticos que se conectam à origem dessa amizade diz respeito à forma com que se identificará a nova cultura, em seu significado mais amplo, ou seja, aos elementos teóricos - e políticos - que tornaram legítimo o projeto de renovação da Bildung. Tanto em um caso como no outro, Wagner atualiza uma herança imprescindível na formação cultural de Nietzsche, que nos remete imediatamente ao romantismo e, em maior ou menor medida, à Aufklärung. No que concerne ao estilo, as mitificações funcionam como um modo de adesão ao discurso reformador, envolvendo signos bastante conhecidos da então recente cultura alemã (destino, gênio, singularidade aristocrática, renovação da raça humana etc.). Quanto à forma, a estética wagneriana revela a matriz que conduz esses signos à sua urgência, à sua intrínseca necessidade.

\section{Wagner e a reforma da cultura}

É conhecido o fato de que é a Ludwig Feuerbach que Wagner deve o título de seu Das Kunstwerk der Zukunft, publicado em 1849: seis anos antes, o filósofo havia escrito Grundsätze der Philosophie der Zukunft, texto que Wagner estudara bem antes de qualquer leitura de Schopenhauer e no qual viu refletida sua tendência humanística, exemplificada pela afirmação que abre o livro: "A tarefa [Aufgabe] do novo tempo foi a realização e a humanização de Deus [Verwirklichung und Vermenschlichung Gottes] - a transformação e dissolução da teologia em antropologia". ${ }^{18}$ Esse humanismo representado por Feuerbach esteve desde muito cedo vinculado à ideia de

considerações fatais para obter concepções esclarecedoras, mas guardá-los para quando o senhor, apesar disso - como eu o conheço - se concentrar e se aprofundar em um trabalho maior e de mais fôlego. Então conhecerá também a palavra correta para os divinos erros de Sócrates e Platão [...]" (BORCHMEYER, D.; SALAQUARDA, J. op. cit., p. 50)

${ }^{18}$ FEUERBACH, L. Grundsätze der Philosophie der Zukunft. Zurich und Winterthur: Verlag des literarischen Comptoirs, 1848, p. 1. Em 1871, ao redigir uma introdução ao terceiro e quarto volumes de seus Sämtliche Schriften, Wagner avalia sua leitura de Feuerbach de então, nos seguintes termos: "Entusiasmado pela leitura enérgica de vários escritos de 
reforma crítica da modernidade - o "novo tempo", conforme ele denomina como tarefa a ser concluída no futuro, sob a condição incontornável de distingui-lo do presente:

\begin{abstract}
As poucas tentativas de reforma na filosofia não se distinguem nada ou quase nada da velha filosofia. A mais imprescindível condição para uma realmente nova filosofia - isto é, independente [selbständigen] - que corresponda às necessidades da humanidade e do futuro é que ela diferencie sua essência [Wesen] toto genere daquela da velha filosofia. ${ }^{19}$
\end{abstract}

Tal comprometimento entre a ideia de espécie e de futuro, elaborada pelo humanismo de Feuerbach, está também na base de desenvolvimentos posteriores muito diversos na filosofia alemã: mantidas as distâncias dessas generalizações, reconhecemos seus ecos no materialismo histórico de Marx e Engels, tanto quanto no positivismo de Eugen Dühring. Mas suas raízes estão localizadas em solo bem mais recuado. Kant já havia feito surgir esse vínculo em sua Resposta à pergunta: o que é a Aufklärung?, em 1783. Nesse artigo, a definição da Aufklärung como "a saída [Ausgang] do homem de sua menoridade, da qual ele próprio é culpado" ${ }^{20}$ devia ser circunscrita pelo horizonte histórico formulado mais adiante, onde Kant sonda sua pertinência:

\begin{abstract}
Quando então for feita a pergunta: vivemos em uma época esclarecida [aufgeklärten Zeitalter]?, então a resposta será: não, mas vivemos em uma época de esclarecimento [Zeitalter der Aufklärung]. Ainda falta muito para que os homens, em seu conjunto, estejam já em uma situação ou possam ser nela colocados, como estão agora as coisas em matéria religiosa [Religionsdingen], que possam fazer uso correto e bom de seu próprio entendimento, sem a direção [Leitung] de qualquer outro. ${ }^{21}$
\end{abstract}

Portanto, se é correto afirmar, como o fez Michel Foucault, que a Aufklärung representa a ruptura que instaura a modernidade - aí incluindo

\footnotetext{
Ludwig Feuerbach, me apossei de diversas designações para conceitos [Bezeichnungen für Begriffe] aos quais eu apliquei uma representação artística [auf künstlerische Vorstellungen anwendete] a que eles nem sempre puderam corresponder claramente. Com isto [...] me refugiei em uma concepção da essência humana na qual acreditava reconhecer claramente minha própria concepção de homem artístico [künstlerichen Menschen]" (WAGNER, R. Sämtliche Schriften und Dichtungen - Volksausgabe, 16 Bände, Leipzig: Breitkopf \& Härtel, 1911, Bd. 3, p. 3).

${ }^{19}$ FEUERBACH, L. op. cit., p. 84 (§ 67).

${ }^{20}$ KANT, I. Beantwortung der Frage: was ist Aufklärung?, Ak 35.

${ }^{21}$ Idem, Ak 40
} 
Wagner e Nietzsche - através de uma problematização em torno do presente e de sua singularidade histórica, ${ }^{22}$ não é menos correto pensar que essa singularidade, muitas vezes formalmente negativa, impõe como tarefa - para a modernidade como um todo - o comprometimento com o futuro, na medida em que é nele que o atual encontra a sua raiz universal: é nele que a ação do presente se investe de sentido.

É bem provável que a leitura de Schopenhauer, empreendida com dedicação por Wagner, na década de $1860{ }^{23}$, tenha acentuado a reação de antagonismo contra sua atualidade, encontrada de maneira elativamente amenizada nos escritos anteriores a essa data. Ela promove uma espécie de conversão intelectual - com todos os signos de entusiasmo que a acompanham - análoga àquela que Nietzsche relata, em suas cartas e escritos autobiográficos. A descoberta da metafísica do belo musical de $O$ mundo como vontade e representação, que colocava a música em posição de independência e predominância em relação às outras artes, foi-lhe extremamente conveniente para as tentativas de justificação filosófica que procurou levar a termo - e, nesse sentido, Beethoven, publicado em 1870, funciona como um atestado dessa conversão. Acentua-se, nesse sentido, a distância entre o presente e o futuro formulada desde seus primeiros escritos: o tom com que se ressalta a urgência de uma reforma contra a modernidade eleva-se gradativamente. Coube a Nietzsche completar o projeto wagneriano com a dimensão que, aos seus olhos, garantiria a universalidade e a cientificidade próprias da filologia e da filosofia, ampliando o campo da reforma estética na direção de uma reforma, a um só tempo, das ciências e das artes. Entre a artificialidade dos modernos - sua falta de uma essência - e a pouco tangível obra de arte do futuro, era necessário revelar uma dimensão onde se pudesse observar efetivamente a apresentação do universal - e, por consequência, da cultura universal a que os homens e, nesse caso, os alemães, deviam estar devotados. Era preciso identificar a pátria do gênio. Essa cultura era a da Grécia antiga, e o modo pelo qual Nietzsche a integrou ao problema do futuro e do presente, em sua reflexão sobre a Bildung, fez surgir uma ideia de reforma cultural muito mais ampla que a proposta por Wagner, por mais que ambos entendessem, em um primeiro momento, que elas pudessem ser coincidentes.

\footnotetext{
${ }^{22}$ Cf. FOUCAULT, M., "Qu'est-ce que les Lumières ?" In: Dits et écrits, vol. IV, Paris : Gallimard, 1994, p. 562-578.

${ }^{23}$ Se acreditarmos em alguns relatos do próprio Wagner, no entanto, é possível que uma primeira leitura tenha ocorrido antes, no outono de 1854 (Cf.: WAGNER, R. "Découverte de Schopenhauer". In: SIPRIOT, P. (Org.). Schopenhauer et la force du pessimisme, p. 158-160).
} 
É claro que Wagner não ignorava os gregos, nem sua importância para os modernos. O texto de A obra de arte do futuro ergue comparações que não deixam a menor dúvida quanto a isso: "Mas diante de qual fenômeno [Erscheinung] nos colocamos com maior sentimento de humilhação da incapacidade de nossa frívola cultura como diante da arte dos helenos?". ${ }^{24}$ Porém aqui, como em toda sua obra, Wagner parece ter nutrido pela Grécia uma espécie de interesse estético característico de todo o século XIX - do qual Nietzsche também não pudera escapar e tenha mesmo feito dele sua profissão - mas seus estudos sobre a vida e a literatura helênicas não parecem ter se aprofundado mais que o suficiente para satisfazer sua tendência erudita em geral, que também partilhava com a aristocracia que lhe era contemporânea. É certo que suas obras musicais se apropriaram frequentemente de temas e estruturas líricas presentes nos trágicos gregos, especialmente em Ésquilo, e lhes deram uma função renovada e importante, mas não maior que, por exemplo, aquelas conferidas às mitologias nórdica e medieval. ${ }^{25}$ Diante dessas prerrogativas, Wagner só pôde compreender a Grécia antiga como exemplo ou, em último caso, como modelo daquilo que ele pretendia definir como cultura. Se quisermos reconduzir a arte grega à universalidade, temos que ultrapassá-la na direção do humanismo - eis a lição feuerbachiana que nos ensina A obra de arte do futuro: "Então temos de ultrapassar a arte helênica na direção da arte humana, para desatar dela as condições [Bedingungen] sob as quais ela foi apenas helênica e não universal [allmenschliche]" ${ }^{26}$ Sob esse aspecto, o futuro é o duplo da Grécia, considerado e purificado pela perspectiva humanista, e exatamente por isso qualquer tentativa de reforma deve se caracterizar como uma revolução. Não uma revolução do tipo imediatamente bélica - várias vezes insistentemente condenada por Wagner - mas uma mais profunda, capaz de renovar a raça humana como um todo: uma Menschheitsrevolution, como indica Die Kunst und die Revolution, em 1849. Essa revolução da humanidade está associada à arte grega - esta é sua raiz, se quisermos regredir ao ponto onde a verdadeira arte tem origem.

${ }^{24}$ WAGNER, R. Das Kunstwerk der Zukunft. In: Sämtliche Schriften und Dichtungen, Bd. 3, p. 62.

${ }^{25}$ Sobre esse ponto, cf. SPENCER, S. "A Idade Média de Wagner". In: MILLIGNTON, B. (Org.). op. cit., p. 185-188. Hugh Lloyd-Jones apresenta um estudo da penetração do pensamento grego na estética wagneriana e conclui: "O quanto a religião e os modos de pensar dos gregos influenciaram Wagner? Com toda certeza muito pouco. [...] O tipo de ordem mundial que Wagner - influenciado pelos Jovens Hegelianos e mais tarde por socialistas e anarquistas - aprovava era muito diferente daquele que se encontra na tragédia grega" (LLOYD-JONES, H. "Wagner e os gregos". In: MILLIGNTON, B. (Org.). op. cit., p. 180-181).

${ }^{26}$ WAGNER, R. Das Kunstwerk der Zukunft. In: Sämtliche Schriften und Dichtungen., Bd. 3, p. 63. 
Todavia, o modo como Wagner entende essa origem é fundamentalmente diferente do de Nietzsche. Ainda muito próximo do hegelianismo, e de Feuerbach, especificamente, a arte grega lhe surge como o ponto de partida historicamente determinado da arte da Europa:

\begin{abstract}
Não podemos dar nenhum passo em uma investigação séria de nossa arte sem encontrarmos sua conexão [Zusammenhang] com a arte dos gregos. Na verdade, nossa arte moderna é apenas um elo na corrente do desenvolvimento da arte [ein Glied in der Kette der Kunstentwickelung] da Europa como um todo, e este tem como origem [ou ponto de partida: Ausgang] os gregos. ${ }^{27}$
\end{abstract}

A revolução da espécie, de que fala, portanto, Wagner, deve significar o ultrapassamento histórico da origem da arte moderna, o ultrapassamento dos gregos, o elo mais primitivo de uma cadeia que se desdobra na direção do futuro. A forma dessa subsunção só pode ser, segundo esses critérios, a revolução: "Apenas a revolução, e não, absolutamente, a restauração pode nos trazer de volta esta arte mais elevada" ${ }^{28}$ E trazer de volta, aqui, não significa fazer renascer a Grécia: "Não, nós não queremos retornar aos gregos, pois foi o que os gregos não sabiam, e por não saberem, que eles tiveram que ir ao chão, disso nós sabemos". ${ }^{29}$ Aquilo que nós, modernos, sabemos signo da diferença histórica em relação aos antigos, à nossa origem - é exatamente o que nos permite olhar retrospectivamente, sem precisar fazer retornar o passado. Se há um vínculo entre o futuro e a origem, ele é essencialmente modelar ou formal.

4 Nietzsche e a reforma da cultura

Em Nietzsche, tudo ocorre de modo fundamentalmente diverso. É para legitimar a proposta wagneriana que ele precisa erguer as teses mais abrangentes sobre a cultura presentes em O nascimento da tragédia e repensar a relação entre a Grécia antiga e os alemães modernos. O livro representa a justificativa filosófica e científica que essa proposta requer aos olhos do filólogo. São bem conhecidas as passagens que articulam a música de Wagner à tragédia grega. Em todas elas, trata-se não de uma renovação baseada no modelo grego, mas do próprio renascimento da universalidade, antes veiculada por esse modelo. O passado, portanto, é a origem e a essência

${ }^{27}$ WAGNER, R. Sämtliche Schriften und Dichtungen, Bd. 3, p. 9.

${ }^{28}$ Idem, p. 30.

${ }^{29}$ WAGNER, R. Sämtliche Schriften und Dichtungen, Bd. 3, p. 30. 
do futuro, e não seu duplo primitivo: eis aí a contrapartida teórica do modo como o encantamento de Nietzsche com Tribschen colocava lado a lado Wagner, Píndaro, Ésquilo e Goethe:

Que ninguém procure enfraquecer nossa fé em um já iminente renascimento [Wiedergeburt] da antiguidade grega; pois somente nela encontramos nossa esperança para uma renovação e purificação [Erneuerung und Läuterung] do espírito alemão através do fogo mágico da música. O que além disso saberíamos nomear que, na atrofia e no cansaço da cultura atual [in der Verödung und Ermattung der jetzigen Kultur], pudesse despertar alguma expectativa consoladora para o futuro ${ }^{30}$

Nota-se, dessa maneira, que o mecanismo político mais importante de O nascimento da tragédia é precisamente a recondução de todos os signos do futuro - esperança, expectativa, fé - à origem extratemporal assinalada pelos gregos. Wagner, como representante dessa linhagem, não é simplesmente o exemplo ou o modelo do gênio de uma cultura verdadeira, mas, sobretudo, a presença ou o signo efetivo de sua possibilidade, tanto quanto a Grécia de Homero ou de Ésquilo não é a forma de expressão com que os modernos devem falar, mas a pátria do universal. Ao contrário do que as teses de A obra de arte do futuro deixam entender, o lugar do artista não é o futuro, sua solidão não é a consequência de ter nascido antes de seu próprio tempo, mas de ter nascido sob o domínio do atemporal. Um projetado prefácio dedicado a Richard Wagner, que Nietzsche escrevera em 1871 para a conferência Sócrates e a tragédia, ${ }^{31}$ resume essa posição, que persiste ao longo de todo O nascimento da tragédia:

[...] me contraria muito procurar o fim [Zweck] da humanidade no futuro dos homens. Nem o estado, nem o povo, nem a humanidade encontram aí seu caminho, mas este está, antes, em seus cumes, o fim [Ziel] está nas grandes "individualidades" ["Einzelnen"], nos santos e nos artistas; portanto, nem antes nem depois de nós, mas fora do tempo [ausserhalb der Zeit]. ${ }^{32}$

Com isso, a tarefa política que se impõe com o projeto de uma reforma cultural é a de desfazer a falsa distância entre o futuro e o passado, resultante da artificialidade do presente, de um modo equivocado de enxergar essas duas dimensões. O gênio, com seu heroísmo trágico, é o signo imperecível

${ }^{30}$ KSA I, 131 (O nascimento da tragédia, 20)

${ }^{31}$ Pronunciada na Basileia, em $1^{\circ}$ de fevereiro de 1870

${ }^{32}$ KSA VII, 354. 
que sustenta a realidade da reforma. Na Alemanha de 1871, é extremamente relevante que esse signo possa ter se apresentado: ele confirma a tese basilar de todos os trabalhos de Nietzsche sobre a Grécia, nesse período; a de que a construção da identidade alemã é a reconstrução do pensamento artísticofilosófico grego, tornada possível não exatamente através de Wagner, mas em Wagner mesmo. É mais ou menos nesses termos que Nietzsche defende essa ideia: "Esse herói futuro [zukünftig Held] do conhecimento trágico trará em sua fronte o reflexo daquela serenidade grega, daquela auréola, com o que inaugurará [inauguriert wird] o iminente renascimento da antiguidade, o renascimento alemão do mundo helênico [die deutsche Wiederbegurt der hellenischen Welt]". ${ }^{33}$ O final da frase resume três dimensões importantes da reforma da cultura, associando-as à ideia da Grécia como origem.

Em primeiro lugar, a reforma representa uma inauguração, mas apenas no sentido em que o novo é, concomitantemente, uma ruptura e um resgate. Em seguida, trata-se de uma reforma inevitável, iminente, e aí é preciso que nos detenhamos um pouco.

Essa concepção atravessa todo o texto das conferências sobre as instituições de ensino: se elas promovem o retrato angustiante da situação presente, é porque elas pretendem revelar a incontornabilidade de uma mudança que se prepara em profundidade. Esse otimismo, que transforma Schopenhauer em Wagner, articula de tal modo a contraposição entre modernidade-aparência / Grécia-universalidade - motivo insistente de praticamente todos os escritos de Nietzsche desse período - que, no final de tudo, a vitória é sempre dada pelo retorno que a força dessa última torna praticamente certo. Tal força é expressa por um conceito que os textos sobre a educação e sobre a Grécia compartilham: o de Tendenz. Em sua primeira filosofia da cultura, Nietzsche compreende a tendência como o dispositivo subterrâneo, a essência mais íntima outorgada à espécie humana - e ao povo alemão, em especial - pela natureza, capaz de assegurar a realização do retorno ao universal. Esse dispositivo recebe algumas vezes a designação mais específica Bildungstendenz: o futuro das instituições de ensino da Alemanha será legitimado através dessa "já existente tendência da cultura [schon vorhandenen Bildungstendenz]" 34, que vencerá justamente porque possui "o maior e mais poderoso aliado: a natureza". ${ }^{35}$ Não podemos esquecer, nesse aspecto, que Schopenhauer e Wagner tinham a mesma fé nessa natureza.

${ }^{33}$ KSA VII, 353. É importante lembrar que Nietzsche escreve essas linhas no momento em que a Alemanha está em guerra pela sua unificação, o que as investe de uma simbologia em torno da redenção heróica extremamente importante.

${ }^{34}$ KSA I, 645

${ }^{35}$ Idem, 646. Um conceito análogo, o de Kulturtendez, aparece no já citado prefácio preparado para Sócrates e a tragédia (KSA VII, 355). 
Por fim, não se trata, pois, de imitação e revolução, mas, antes de tudo, de identificação e restauração. O renascimento do mundo helênico só ganha seu sentido mais amplo por ser alemão. A construção da Alemanha não pode se limitar à imitação de um passado histórico, como o fazem os professores universitários amantes do historicismo. É preciso converter a própria ideia de mímeses, como mostrou Philippe Lacoue-Labarthe a esse respeito: se é possível falar de imitação, isso se dá somente na medida em que o objeto a ser imitado seja um e o mesmo em relação ao imitador - entre ambos, não deve haver a interferência de uma instância histórica, pois "os gregos, dito de outra forma, não pertencem à história, não são seres históricos. E é somente nisso que são dignos de serem imitados". ${ }^{36}$

Portanto, se a cultura deve, de alguma forma, se voltar para o sol do wagnerianismo, é porque, entregue à obscuridade com que se contaminou o espírito alemão - ao eruditismo inútil, à prosa jornalística e a todas as outras marcas de decadência e miséria, expostas nas conferências sobre a educação - ela já não consegue enxergar o que sempre esteve ali. O extemporâneo, unzeitgemässig - adjetivo que, não aleatoriamente, Nietzsche usa em primeiro lugar a respeito de Wagner ${ }^{37}$ - é a medida corretiva dessa cegueira: se há luta na reforma da Bildung, ela não é aquela da vingança do futuro que vem instaurar seu reino, mas a de um fora-do-tempo, daquilo que não está adequado (gemäss) ao tempo e que vem reivindicar seus direitos contra os modernos. $\mathrm{O}$ futuro, como esfacelamento da dicotomia presente-passado, pertence a esses homens que souberam enxergar Wagner. A colocação da primeira pedra do teatro de Bayreuth, em 1872, será compreendida por Nietzsche, de forma extremamente entusiástica, como o acontecimento que reúne em si todas as dimensões do retorno da Bildung. Como inauguração, ela é o resgate do universal que os gregos apresentavam - conjuga futuro e presente sob a incontornabilidade da origem - e, com o mesmo gesto, funda uma sociedade que se relaciona diretamente com esse universal, uma sociedade que não se adequará mais ao tempo. Bayreuth é a realização da aristocracia ideal, o ponto mais alto de uma sociedade pensada por Nietzsche, ao final de toda uma série de recusas em direção aos mais diversos meios culturais. Se Nietzsche se entregou com tanta devoção ao projeto de edificação do teatro de Bayreuth, é exatamente porque pensava que ele poderia realizar as reformas tão amplas e profundas sugeridas em seus textos desse período. Em suma, "todos aqueles

\footnotetext{
${ }^{36}$ LACOUE-LABARTHE, P. Histoire et mimèses. In : L'imitation des modernes Typographies II. Paris: Galilée, 1986. p.103.

${ }^{37}$ Em carta de 15 de agosto de 1869, a Rhode: "<Wagner> está sempre lá, enraizado através de sua força, com seu olhar sempre fixo por cima de tudo o que é efêmero [über alles Ephemere], e extemporâneo no mais belo sentido [unzeitgemäss im schönsten Sinne]". KSB III, 42.
} 
que participarem do festival de Bayreuth serão sentidos como homens extemporâneos [unzeitgemässe Menschen]: sua pátria [Heimat] está em outro lugar no tempo [...]"38.

Entre a filosofia de Nietzsche e a estética de Wagner, todos os elementos conceituais envolvidos estão sujeitos a uma espécie de margem de equivocidade, especialmente pelo modo como representaram apropriações e redimensionamentos dos conhecidos jargões românticos. Assim, quando Wagner pensa em revolução, ele associa o termo à ideia de ultrapassamento do presente, mas também do passado. E, se Nietzsche pensa em restauração da arte grega, não é, certamente, segundo o modelo simplesmente mimético que Winckelmann havia elaborado, muito menos o do teatro de Schiller, que pretendia trazer para os palcos modernos o ideal formal da tragédia clássica. O fato é que havia, entre os dois, demasiado burburinho nacionalista, demasiado entusiasmo artístico para que essas diferenças fossem sequer pressentidas, ao menos em um primeiro instante. Seja como for, no projeto de Nietzsche, a aristocratização e a reforma se coadunam com a ideia de resgate, de restauração. O futuro não impõe simplesmente a revolução da humanidade, da qual Wagner se fez porta-voz. Há aí uma teoria da cultura muito mais sofisticada: a identidade cultural da Alemanha à qual ela está associada se fundamenta em uma origem que confirma sua vocação para o futuro. Não o futuro pouco tangível da estética wagneriana, comprometida em demasia com seu presente, mesmo de forma negativa. Tentar transformar esses dois pensamentos em uma única filosofia talvez tenha sido o primeiro "erro" de tradução operado por Nietzsche, em torno de Wagner - "erro" do qual, contudo, sua filosofia da cultura retirou grande parte de sua positividade.

BRITTO, Fabiano de Lemos. Nietzsche and the messianic construction of wagnerianism. Trans/Form/Ação, (Marília); v.33, n.2, p.113-128, 2010.

ABSTRACT: The history of the ambiguous relationship between Nietzsche and Wagner reveals all dimensions of this fragile tension when considered accordingly to the elements from which both considered the problem of culture and its renewal as political and theoretic mission. This paper intends, by reading some testimonial documents, to stress the ideological distance that both the philologist and the composer, strategically, had to ignore. The differences between their culture reform projects can, through this analysis, be demonstrated - with regards to political acting as well as to a worldview.

KEYWORDS: Nietzsche. Wagner. Culture. Bildung

${ }^{38}$ KSA I, 434 


\section{Referências}

BORCHMEYER, D.; SALAQUARDA, J. Nietzsche und Wagner: Stationen einer epochalen Begegnung, Band 1: Briefwechsel. Frankfurt a. M.: Insel, 1994.

FEUERBACH, L. Grundsätze der philosophie der zukunft: Zurich und Winterthur: Verlag des literarischen Comptoirs, 1848.

FÖRSTER-NIETZSCHE, E. Wagner und Nietzsche zur Zeit ihr Freundschaft. München: [s.n.], 1915.

FOUCAULT, M. Qu'est-ce que les Lumières? In: Dits et écrits. Paris: Gallimard, 1994. v. 4.

GREGOR-DELLIN, M. Richard Wagner: Sein Leben - Sein Werk - Sein Jahrhundert. München: Piper, 1980.

KANT, I. Werke in zwölf Bänden. Frankfurt a. M.: Suhrkamp, 1977.

MILLIGNTON, B. (Org.). Wagner: um compêndio. Rio de Janeiro: Jorge Zahar, 1994.

NIETZSCHE, F. Sämtliche Briefe. Kristische Studienausgabe in 8 Bänden, Hrgb. von Giorgio Colli und Mazzino Montinari. Munchen: Deutscher Taschenbuch Verlag und Walter de Gruyter, 1986. (=KSB)

Sämtliche Werke. Kristische Studienausgabe in 15 Bänden. Hrgb. von Giorgio Colli und Mazzino Montinari. Munchen: Deutscher Taschenbuch Verlag und Walter de Gruyter, 1980. (= KSA)

Werke: historisch-Kritisch Gesamtausgabe, 5 Bände. Hrgb. von H. J. Mette und K. Schlechta. München: C. B. Beck, 1933-1942. (= HKG).

SIPRIOT, P. (Org.). Schopenhauer et la force du pessimisme. Paris: Éditions Du Rocher, 1988.

WAGNER, C. Die Tagebücher, 2 Bände. München: Piper, 1976-1977.

WAGNER, R. Briefe in Originalausgabe, 2 Folge. Leipzig: Breitkopf \& Härtel, 1912.

Sämtliche Schriften und Dichtungen - Volksausgabe, 16 Bände. Leipzig: Breitkopf \& Härtel, 1911. 